\title{
Barriers to Evidence Based Nursing Practice in Tertiary Care Hospitals of Peshawar, Pakistan
}

\author{
Aurang Zeb*, Mehwish Riaz, Sireeta Emmanual, Nazia Rehman, Saima Qudrat and Rubina \\ Student Post RN BScN Rehman Collage of Nursing, Pakistan
}

Received: 眥 August 08, 2018; Published: 眥 August 16, 2018

*Corresponding author: Aurang Zeb, Assistant Professor, Rehman Collage of Nursing, Hayatabad Peshawar, UAN: 111-REHMAN, Pakistan

\section{Abstract}

The study was intended to examine Perceived Barriers to evidence based nursing. The study was conducted in Khyber teaching hospital and Rehman medical institute Peshawar. By using Rao-soft sample size calculator the size of sample was 94 from total 285 population. A selfadministered questionnaire with 24 items was applied on nurses in the stated hospitals. The identified barriers to evidence based nursing practice were insufficient time, no access to research materials, and no authority to change patient care, inadequate facilities and unavailability of equipment. Awareness to the importance of evidence based nursing practice is the need of the day, the Government and health authorities shall do all the possible action for the availability of necessary equipment and policies for the implementation of EBP.

\section{Introduction}

Due to increased expectations of high quality nursing care in society, it is no longer acceptable for nurses to deliver nursing care based only on experience and textbook knowledge; but, to provide quality nursing care based on research findings. But still a gap exist between the knowledge of evidence based practice and its implementation. Evidence based practice was known as "evidence based medicines" in 1980s; later on, the word changed to "evidence based practice." The purpose was to identify the importance of scientific evidences in clinical areas Melnyk. Professional nurses of the $21^{\text {st }}$ century is facing many challenges within the dynamic state of health care setting.

Some of these challenges are lack of resources, lack of conducive teaching environment, the attitude toward research, lack of knowledge of research and specifically low level of knowledge and compliance to "evidence-based nursing practice." Nurses in the developing world even do not know evidence based practice. An investigation carried out by the National Board of Health and Welfare in Sweden revealed that $8.6 \%$ of patients were injured during hospital care. These injuries were judged to have been avoidable if actual knowledge had been applied.

\section{Evidence}

It's defined as anything presented in support of an assertion. This support may be strong or weak. The strongest type of evidence is that which provides direct proof of the truth of an assertion. Evidence Based Practice: Clinical nurses are expected to systemically gather the best research evidence drawn from nursing experiences and consider patient's preferences when they are making professional decisions. This is known as evidence based practice. Evidence based practice has been recognized by the health care community as the gold standard for the provision of safe and compassionate health care. Evidence based practice improves the quality of care and patient safety. Factors influencing EBP have been extensively reported. Individual nurse qualities include EBP beliefs, confidence, time, knowledge, and skills Melnyk. Clinical nurses' varying backgrounds, education, and attitudes can influence their motivation and ability to integrate evidence into practice Swenson-Britt \& Berndt.

Organizational qualities that impact EBP include administrative support and access to resources (Melnyk. Two categories of organizational factors are infrastructure aspects such as library resources, and unit or facility climate such as authority to make changes, resistance or support by colleagues and leaders. Consistently cited barriers to research utilization are organizational factors and difficulty in understanding research findings [3]. A study on evidence-based practice conducted by Susan in Sweden has highlighted the overall positive attitude of nurses towards evidence-based practice and decision making. The result showed a statistically significant difference in the professional groups regarding personal attitudes towards, use of, and perceived benefits from and limitations of evidence-based practice. One of the studies identified the barriers, desire and ability for evidencebased practice Funk et al. [1]. This study showed that nurses with higher education have positive response towards evidence-based practice. Availability of resources is also one of barrier. 
A study by Umarani [2] at University of California highlighted barriers to Evidence based nursing resulted are low level of knowledge, lack of time, unavailability of recourses, organizational culture, lack of administrative support, unclear workplace expectations and poor understanding of statistics. A review of the literature revealed that nurses from different countries and settings have consistently been complaining of similar barriers to the adoption of EBP, which include lack of time, perception of insufficient power to adjust patient care processes, inadequate organizational support, insufficient access to research journals and articles and insufficient knowledge and skills Carroll et al. [4-8]. Organizations must prioritize evidence-based practice if patients are to receive the best available care.

\section{Methodology}

\section{Research Design}

Descriptive cross-sectional study was used in the research study. The study was conducted during the months of February to May 2018 in Khyber Teaching hospital and Rehman Medical Institute Peshawar [9-15].

\section{Study Setting}

This research project was conducted in Khyber Teaching Hospital and Rehman Medical Institute Peshawar.

\section{Study Population}

Population for this study was registered nurses, working in Khyber teaching hospital and Rehman Medical Institute Peshawar. The total population of nurses in both the hospital was 285 .

\section{Sampling Technique}

Simple random sampling technique was used for sample selection in this research project to easily access to nurses of KTH and RMI Peshawar [16-18].

\section{Sample Size}

Sample size was calculated by RAO software, population size was 285 with the margin of error $5 \%$ and non-responsive rate $10 \%$ and calculated sample size was 94 .

\section{Inclusion Criteria}

All registered nurses with Diploma in Nursing/ BSN

\section{Exclusion Criteria}

Nurses in management/ supervisor/head nurses

\section{Data Collection Tool}

The tool used for this study was adopted from Funk et al. [1], and Upton and Upton. This questionnaire was also applied on $10 \%$ of the sample size as pilot study, and the outcome was almost the same as the applied for main data collection [18-20].

\section{Data Collection Procedure}

Written questionnaire was distributed among the nurses of Khyber Teaching Hospital and Rehman Medical Institute Peshawar. And their response were asked for.

\section{Ethical Consideration}

Written permission was obtained from Nursing Director of Khyber teaching hospital and chief Nurse of RMI Peshawar. Informed consent was distributed among participants of this research project. Confidentiality and anonymity were assured throughout the study.

\section{Data Analysis}

Data was entered and analyzed by using SPSS version 21 . Frequencies and percentages were calculated for categorical variables and mean with standard deviation were calculated for continuous variables in the descriptive statistics. Independent sample T-test and chi-square was applied in inferential statistics [21-22].

\section{Results}

\section{Response Rates}

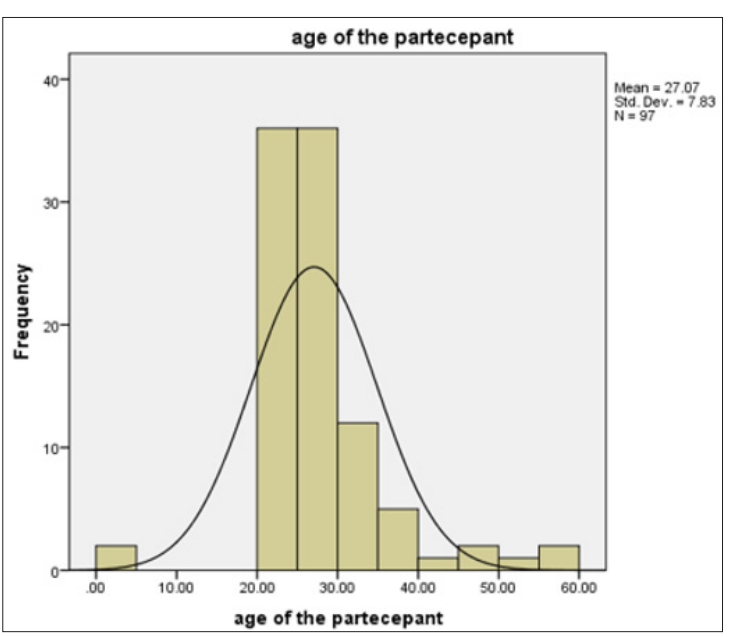

Figure 1: The experience varied with mean of $7.06+10.83$. (chart 1.3)

Based on professional qualification the respondent was divided into 03 categories diploma $(70 \%)$ Baccalaureate $(18.6 \% ; \mathrm{n}=97)$ and Post RN $(11.3 \%)$. Chart 1.4

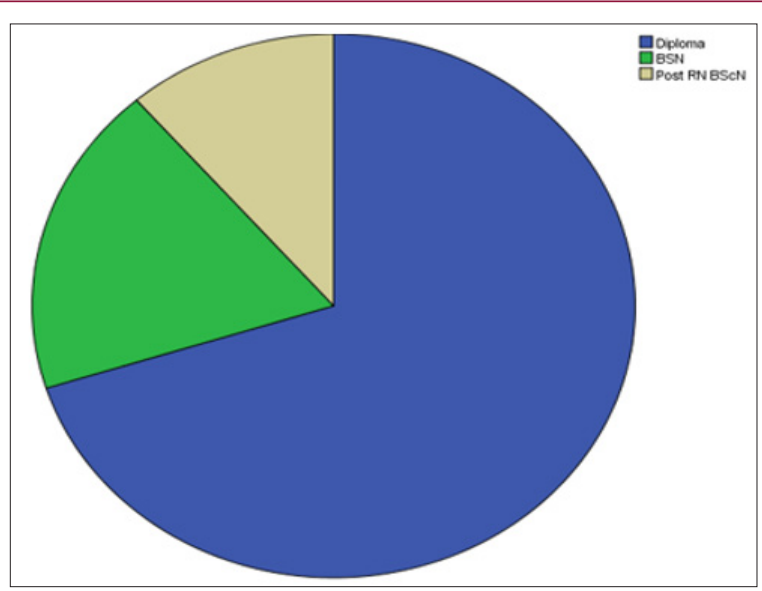

Figure 2: Nurses were asked to respond to the following question, "To what extent do the following factors are barriers to nurses' use of research findings in day-to-day practice (Table 1.1). 
Table 1: The most frequently identified barriers reported in the current study are as follow:

\begin{tabular}{|c|c|c|c|}
\hline S\# & Questions & Yes\% & No\% \\
\hline 1 & Do you often have insufficient time on job to implement new ideas? & 77.3 & 22.7 \\
\hline 2 & Do you have sufficient access to research materials? & 40.2 & 59.8 \\
\hline 3 & Is research readily available? & 33 & 66 \\
\hline 4 & Do you have authority to change patient care? & 55.7 & 44.3 \\
\hline 5 & $\begin{array}{l}\text { Are the management and staff of your institute supportive for implementations of any change in } \\
\text { policy? }\end{array}$ & 68 & 32 \\
\hline 6 & Do physicians cooperate with you in implementation of EBP? & 64.9 & 34.1 \\
\hline 7 & Do all the researches generalizable to your setting? & 45.4 & 54.6 \\
\hline 8 & Are the facilities and equipment always adequate? & 54.6 & 45.4 \\
\hline 9 & Does administration allow implementation? & 59.8 & 40.2 \\
\hline 10 & Is relevant literature complied in a place that is accessible? & 46.4 & 53.6 \\
\hline 11 & Is research reported clearly or readably? & 62.9 & 36.1 \\
\hline 12 & Implications for practice not clear? & 51.5 & 47.4 \\
\hline 13 & Is research relevant to nurse's practice? & 79.4 & 20.6 \\
\hline 14 & Are you unaware of EBP? & 38.1 & 60.8 \\
\hline 15 & Are you capable to evaluate quality of research? & 81.4 & 18.6 \\
\hline 16 & Do your colleagues know about EBP? & 67 & 32 \\
\hline 17 & Do you think that benefits of changing practice are minimal? & 48.5 & 51.5 \\
\hline 18 & Are you willing to change existing or try new ideas? & 91.8 & 8.2 \\
\hline 19 & Do you see little benefit for yourself from EBP? & 67 & 32 \\
\hline 20 & Do you value of research for practice? & 83.5 & 16.5 \\
\hline 21 & Are you uncertain about the results of EBP? & 43.3 & 55.7 \\
\hline 22 & Do you think that literature reports conflicting results? & 54.6 & 45.5 \\
\hline 23 & Is research published fast enough? & 35.1 & 63.9 \\
\hline 24 & Do you think that research available to you has methodological inadequacies? & 58.8 & 41.2 \\
\hline
\end{tabular}

a. $\quad 77.3 \%$ nurses have insufficient time on job to implement new ideas.

b. $\quad 59.8 \%$ nurses have insufficient access to research materials.

c. $60 \%$ said that research materials are not available

d. $\quad 45.3 \%$ nurses don not have the authority to change patient care.

e. $\quad 45.4 \%$ perceive the unavailability of facilities and equipment.

f. $40 \%$ do not know about EBP.

Out of total 97 participants 55 were from RMI and 42 were from KTH. $73.2 \%$ was female and the remaining was male. The age of the participants was mean of $(27.7 \%+7.83)$ (Figure $1 \& 2)$ and (Table 1).

\section{Discussion}

$60 \%$ of nurses knows about the concept of EBP but this study revealed that there are certain barriers that limits evidence-based practice in clinical setting. The most common barrier is insufficient time followed by limited resources and equipment, unsupportive administration to implement evidence based practice, and somehow literature is not related to nursing practice. The current study identified some of factors, which facilitate or hinder RNs to implement EBP. Some of the factors were insufficient time on job to implement new ideas, workload of RN and professional networks that influenced RN ability to promote EBP. Insufficient research materials also influenced as barriers of EBP. Lack of resources such as human resource, financial support, access, equipment, time, and evidence were among the common issues. The limited number of staff and, in particular, access to advanced practice was also of concern.

Nursing staff, in particular registered nurses (RNs) is the largest health professional group in all sectors of healthcare. The majority of RNs work in direct care of patients; they assess patients' needs and make decisions on nursing interventions. RNs' practice of EBP can be assumed to have a major impact on patients' outcomes and safety. Another barrier to EBP that has been commonly identified in research studies is the perception of insufficient power to adjust patient care processes. For example, Umarani [2] surveyed 100 registered nurses in India to determine the reasons why they failed to use research findings in clinical practice. Results from that study revealed that $72 \%$ of respondents perceived what this paper contributes to the wider global clinical community. In contrast, the 
current study identified that only $55.7 \%$ nurses have authority to change patient's care. Hence, there is a potential to improve the patient care, as well as organizational factors such as supportive leadership, organizational climate and access to resources, which are associated with practice of EBP. The study also revealed that $54.6 \%$ sample agreed about the adequacy.

Item no 13 of the questionnaire indicates that $79.4 \%$ sample agrees on relevancy of nursing practice which means that all the nursing is excavated from EBP. The results of the current study are compared with the study by Gerrish et al. [6] conducted at public hospital Singapore which revealed that lack of time, multiple resources of literature, not having authority to change patient care/ procedures. It's not only lack of time to study but limited searching, understanding and implementing evidence based practice. The unsupportive administration also plays important role as it does not allow bringing changes and implementing new ideas. The results of the study Umarani [2] conducted at University of California correlates with the results of the current study. The study highlighted insufficient time, lack of authority and understanding statistical analysis as the common and significant barriers to Evidence Based Practice.

\section{Conclusion}

Although EBP has been highlighted as a core competency of health professionals, the group of RNs in the current study reported a low extent of practicing EBP. There is obviously a need to develop strategies to support RNs in order to enhance their skills and practice of EBP. The study revealed that insufficient time, lack of autonomy and unsupportive administration are the major barriers to evidence based practice. It has been concluded that such a policy should be made that RNs should get proper time and support from administration so that nurses practice evidence based nursing.

\section{References}

1. Funk SG, Champagne MT, Wiese RA, Tornquist EM (1991) BARRIERS: the barriers to research utilization scale. Appl Nurs Res 4(1): 39-45.

2. Umarani J (2014) A study to assess the Perceived barriers to Evidence Based Practice among Registered Nurses. Asian Journal of Biomedical and Pharmaceutical Sciences 4(32): 15-19.

3. Heiwe S, Kajermo KN, Tyni Lenné, R Guidetti S, Samuelsson M, et al. (2011) Evidence-based practice: attitudes, knowledge and behavior among allied health care professionals. Int J Qual Health Care 23(2): 198-209.

4. Baird LM, Miller T (2015) Factors influencing evidence-based practice for community nurses. Br J Community Nurs 20(5): 233-242.

5. Carroll D, Greenwood R, Lynch KE, Sullivan JK, Ready CH, et al. (1997) Barriers and facilitators to the utilization of nursing research. Clin Nurse Spec 11(5): 207-212.

6. Gerrish K, Cooke J (2013) Factors influencing evidence-based practice among community nurses. J Community Nurs 27(4): 98-101.
7. Jordan P, Bowers C, Morton D (2016) Barriers to implementing evidence-based practice in a private intensive care unit in the Eastern Cape. Southern African Journal of Critical Care (Online) 32(2): 50-54.

8. Mallion J, Brooke J (2016) Community-and hospital-based nurses' implementation of evidence-based practice: are there any differences. Br J Community Nurs 21(3): 148-154.

9. Brown CE, Wickline MA, Ecoff L, Glaser D (2009) Nursing practice, knowledge, attitudes and perceived barriers to evidence-based practice at an academic medical center. J Adv Nurs 65(2): 371-381.

10. Carroll DL, Greenwood R, Lynch KE, Sullivan JK, Ready CH, et al. (1997) Barriers and facilitators to the utilization of nursing research. Clin Nurse Spec 11(5): 207-212.

11. Dogherty EJ, Harrison MB, Graham ID, Vandyk AD, Keeping Burke L (2013) Turning knowledge into action at the point-of-care: The collective experience of nurses facilitating the implementation of evidence-based practice. Worldviews Evid Based Nurs 10(3): 129-139

12. Funk SG, Champagne MT, Wiese RA, Tornquist EM (1991) BARRIERS: the barriers to research utilization scale. Appl Nurs Res 4(1): 39-45.

13. Gerrish K, Nolan M, McDonnell A, Tod A, Kirshbaum M, Guillaume L (2012) Factors influencing advanced practice nurses' ability to promote evidence-based practice among frontline nurses. Worldviews Evid Based Nurs 9(1): 30-39.

14. Mallion J, Brooke J (2016) Community-and hospital-based nurses' implementation of evidence-based practice: are there any differences. Br J Community Nurs 21(3): 148-154.

15. Mehrdad N, Salsali M, Kazemnejad A (2008) The spectrum of barriers to and facilitators of research utilization in Iranian nursing. J Clin Nurs 17(16): 2194-2202

16. Mehrdad N, Salsali M, Kazemnejad A (2008) The spectrum of barriers to and facilitators of research utilization in Iranian nursing. J Clin Nurs 17(16): 2194-2202.

17. Mohsen MM, Safaan NA, Okby OM (2016) Nurses' perceptions and barriers for adoption of evidence based practice in primary care: Bridging the gap. Am J Nurs Res 4(2): 25-33.

18. Solomons NM, Spross JA (2011) Evidence-based practice barriers and facilitators from a continuous quality improvement perspective: an integrative review. J Nurs Manag 19(1): 109-120.

19. Underhill M, Roper K, Siefert ML, Boucher J, Berry D (2015) EvidenceBased Practice Beliefs and Implementation Before and After an Initiative to Promote Evidence-Based Nursing in an Ambulatory Oncology Setting. Worldviews Evid Based Nurs 12(2): 70-78.

20. Wilson M, Sleutel M, Newcomb P, Behan D, Walsh J, et al. (2015) Empowering Nurses with Evidence-Based Practice Environments: Surveying Magnet $\AA^{\circledR}$, Pathway to Excellence $®$, and Non-Magnet Facilities in One Healthcare System. Worldviews Evid Based Nurs 12(1): 12-21.

21. Yip WK, Zubaidah SM, Shen L, Ang EN, Zhang X, et al. (2013) Nurses' perception towards evidence-based practice: a descriptive study. Singapore Nurs J 40(1): 34-41.

22. Zhou F, Hao Y, Guo H, Liu H (2016) Attitude, knowledge, and practice on evidence-based nursing among registered nurses in traditional Chinese medicine hospitals: A multiple center cross-sectional survey in China. Evid Based Complement Alternat Med. 


\section{ISSN: 2574-1241}

DOI: $10.26717 / B J S T R .2018 .08 .001592$

Aurang Zeb. Biomed J Sci \& Tech Res

CC (P) This work is licensed under Creative

Submission Link: https://biomedres.us/submit-manuscript.php

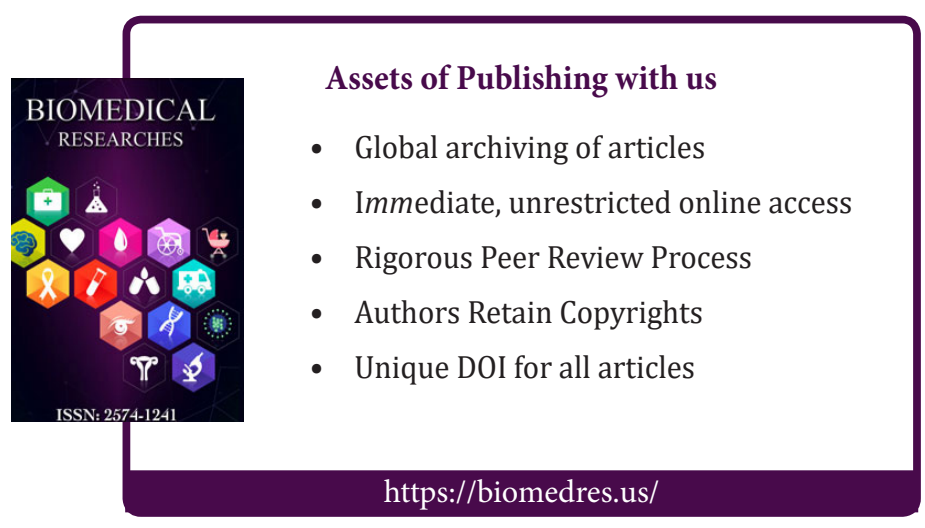

